\title{
A STUDY ON BIOCHEMICAL CHANGES OF ATHEROSCLEROSIS IN PREDIABETICS AND DIABETICS
}

\author{
Nandita Hazra1, Nirmalya Roy2, Chittaranjan Maity 3 \\ ${ }_{1}^{1}$ Post Graduate Trainee, Department of Biochemistry, KPC Medical College and Hospital, Kolkata. \\ ${ }^{2}$ Associate Professor, Department of Medicine, KPC Medical College and Hospital, Kolkata. \\ 3 Professor, Department of Biochemistry, KPC Medical College and Hospital, Kolkata.
}

\begin{tabular}{l}
\hline ABSTRACT \\
BACKGROUND \\
Diabetic dyslipidaemias cause coronary heart disease, cerebrovascular disease and other complications of atherosclerosis thus \\
leading to high mortality and morbidity in type 2 diabetics. But diabetic dyslipidaemia starts even before the onset of diabetes thus \\
indicating the role of prediabetes as an atherosclerotic marker.
\end{tabular}

\section{AIMS, SETTINGS AND DESIGN}

In this study, we have tried to evaluate the dyslipidaemia associated with the type 2 diabetes mellitus and prediabetes and also the correlation between carotid artery intima media thickness (CIMT) with lipid profile in prediabetics and diabetics in a ho spital based case control study consisting of $57(42 \%)$ diabetics, 45 (33\%) prediabetics and $34(25 \%)$ healthy subjects within a span of one year.

\section{METHODS}

Fasting glucose, postprandial glucose, total serum cholesterol (TC), high density cholesterol (HDL-c) and triglyceride (TG) were measured by standard pre-validated photometric tests as applicable. HbA1c or glycated haemoglobin was measured by HPLC (High Performance Liquid Chromatography). CIMT was measured by B mode ultrasonography.

\section{STATISTICAL ANALYSIS}

The data obtained were analysed using the statistical software, SPSS version 16 . An alpha level of $5 \%$ has been taken, i.e. if any $\mathrm{p}$ value is less than 0.05 it has been considered as significant.

\section{RESULTS AND CONCLUSION}

In our study, the plasma total cholesterol, triglyceride, low density cholesterol (LDL-c) and very low density cholesterol (VLDLc) increased while plasma HDL-c decreased from Healthy to Prediabetes to Diabetes. CIMT also increased from Healthy to Prediabetes to Diabetes. Total cholesterol, triglyceride and LDL-c correlated positively, strongly and significantly with CIMT while HDL-c correlated negatively, strongly and significantly with CIMT in Healthy and Diabetics, but not in Prediabetics. Thus emphasising that though biochemical changes of atherosclerosis starts much before the onset of diabetes, in the prediabetes state only; but the insignificant correlation of lipid parameters with the Composite CIMT in the prediabetes population indicates that CIMT is not yet highly raised in the prediabetes state.

\section{KEYWORDS}

Diabetic Dyslipidaemia, Prediabetes, Atherosclerosis, Lipid Profile, Carotid Intima Media Thickness.

HOW TO CITE THIS ARTICLE: Hazra N, Roy N, Maity C. A study on biochemical changes of atherosclerosis in prediabetics and diabetics. J. Evolution Med. Dent. Sci. 2016;5(35):2036-2041, DOI: 10.14260/jemds/2016/478

\section{INTRODUCTION}

The term Diabetes Mellitus (DM) describes a heterogeneous group of metabolic disorder which is characterised by chronic hyperglycaemia and disturbances of carbohydrate, fat and protein metabolism resulting from defects in insulin secretion, insulin action, or both. ${ }^{1}$ In 2014 , according to the International Diabetes Federation, an estimated 387 million people all over the World had DM with 75 million alone in the South East Asia, while $46.3 \%$ of the population remain undiagnosed for DM.2 Diabetic dyslipidaemias are the common cause for development of coronary heart disease, cerebrovascular disease and other complications of atherosclerosis leading to the high mortality and morbidity in Type 2 DM patients. ${ }^{3}$

Financial or Other, Competing Interest: None.

Submission 14-03-2016, Peer Review 10-04-2016,

Acceptance 16-04-2016, Published 02-05-2016.

Corresponding Author:

Nandita Hazra,

46/3, Nimchand Moitra Street,

Kolkata-700035.

E-mail: nanditahazra@gmail.com

DOI: $10.14260 /$ jemds $/ 2016 / 478$
Diabetic dyslipidaemia or atherogenic dyslipidaemia consists of moderate elevation in triglyceride (TG) levels, small dense low density lipoprotein cholesterol (LDL-c) particles and low high density lipoprotein cholesterol (HDLc) values. ${ }^{4}$ But, diabetic dyslipidaemia starts even before the onset of diabetes and is associated with insulin resistance. 4 Small dense LDL-c particles are highly atherogenic because of their enhanced susceptibility to oxidative modification and increased uptake by the arterial wall. ${ }^{4}$

Although atherosclerosis is a progressive disorder of the arterial wall involving inflammation, vascular lipid deposition and remodelling, fibrosis, and thrombosis, ${ }^{5,6}$ it does not progress in a uniform manner, thus leading to a plethora of complications including cardiovascular disease. ${ }^{7}$ The concept of pre-diabetes started building up since 1979 when the National Diabetes Data Group introduced the concept of "Impaired Glucose Tolerance" (IGT). Prediabetes was defined by a state midway between the normal glucose homeostasis and the diseased condition of Diabetes Mellitus. 8,9 
Almost two decades later in 1997, the International Expert Committee (IEC) on the Diagnosis and Classification of Diabetes Mellitus introduced the concept of "Impaired Fasting Glucose" (IFG).

IFG and IGT represent different pathophysiological and biochemical process and these were grouped together, as a common clinical entity, termed as "Prediabetes".10,11 This marked the logical conclusion of the natural history of diabetes representing the continuum in metabolic dysregulation which kept worsening as the disease progresses or went unchecked. Various longitudinal studies showed a clear association between various macrovascular complications of prediabetes, most notable among them being the cardiovascular complications. ${ }^{12}$ However, the role of prediabetes (IFG or IGT) as an atherosclerotic risk factor as well as its influence on lipid metabolism is still not well defined. The relationship between lipid metabolism with prediabetes is poorly defined. The relation between lipid changes with intima media thickness- all determinants of cardiovascular disease is also unsettled in prediabetes and diabetes.

Carotid intima media thickness (CIMT) is considered a recognised surrogate marker for assessing cardiovascular risk and recognising the subclinical atherosclerosis. The American Heart Association (AHA), the National Cholesterol Education Program(NCEP) expert panel and the European Third Joint Task Force recommend the use of non-invasive, quick and cost-effective screening test, CIMT by ultrasound method, for identifying abnormal arterial structure and atherosclerosis. ${ }^{13}$ CIMT using high frequency ultrasound (10 $\mathrm{MHz}$ ) accurately measures the arterial wall thickness ${ }^{14}$ and is extremely accurate as compared to histologic examination. ${ }^{15}$ So, this study aims for the lipid profile changes of atherosclerosis in diabetes and prediabetes. It also aims to see the correlation of Carotid Intima Media Thickness (CIMT) with lipid profile.

\section{AIMS AND OBJECTIVES}

- To study lipid profile in prediabetics and diabetics.

- To determine the correlation between carotid artery intima media thickness with serum total cholesterol, triglyceride, HDL cholesterol and LDL cholesterol level in prediabetics and diabetics.

\section{MATERIALS AND METHODS}

A cross-sectional, observational, descriptive study was conducted on adult patients ( $>18$ years of age), irrespective of sex, attending the outpatient department and admitted in the inpatient wards of the Department of Medicine of a Tertiary Care Medical College Hospital, West-Bengal, India from a period of July 2014 to June 2015 after taking Institutional ethical clearance. ICMR's Ethical Guidelines for biomedical research on human participants, (2006) and the Helsinki Declaration 1975, revised in 2000 was followed. Only those who met the study criteria as outlined in inclusion criteria and exclusion criteria were included in the study. 136 patients were included in our study and 447 patients were excluded according to the inclusion and exclusion criteria of our study.

\section{Inclusion Criteria}

Patients who met the definition of Prediabetes (IFG or IGT or HbA1C-5.7\%-6.4\%) and Diabetes Mellitus as outlined by the
International Expert Committee formed by the American Diabetes Association, the European Association for the Study of Diabetes, and the International Diabetes Federation were included in the study. ${ }^{16}$ Healthy controls were also included in the study. The Criteria are:

\section{Criteria for Diagnosis of Prediabetes \\ - Impaired Fasting Glucose (IFG) \\ Fasting Plasma Glucose: 100 to $125 \mathrm{mg} / \mathrm{dL}$ (5.6-6.9 $\mathrm{mmol} / \mathrm{L})$.}

\section{OR}

\section{- Impaired Glucose Tolerance (IGT)}

Fasting Plasma Glucose less than $100 \mathrm{mg} / \mathrm{dL} \quad(5.6$ $\mathrm{mmol} / \mathrm{dL}$ ).

Two-hour plasma glucose level after 75-g oral glucose intake: 140 to $199 \mathrm{mg} / \mathrm{dL}$.

OR

- HbA1c :5.7\% to $6.4 \%$

Criteria for Diagnosis of Diabetes

- HbA1c or Glycated haemoglobin $\geq 6.5 \%$.

OR

- $\quad$ Fasting Plasma Glucose $>126 \mathrm{mg} / \mathrm{dL}$.

\section{OR}

- 2-Hour plasma glucose $>200 \mathrm{mg} / \mathrm{dL}(11.1 \mathrm{mmol} / \mathrm{L})$ after oral glucose intake. The test was performed as described by the World Health Organization, using a glucose load containing the equivalent of $75 \mathrm{~g}$ anhydrous glucose dissolved in water.

\section{OR}

- In a patient with classic symptoms of hyperglycaemia or hyperglycaemic crisis, a random plasma glucose $>200 \mathrm{mg} / \mathrm{dL}$ (11.1 mmol/L).

\section{Criteria for Diagnosis of Healthy}

- Fasting Plasma Glucose: $<100 \mathrm{mg} / \mathrm{dL}$ (5.6 mmol/L).

- Two- hour plasma glucose level after $75 \mathrm{~g}$ oral glucose intake: $<140 \mathrm{mg} / \mathrm{dL}$.

- HbA1c: $<5.7 \%$.

\section{Exclusion Criteria}

- History of diabetes or history of intake of any hypoglycaemic agent.

- History of hypertension.

- History of severe renal, hepatic, pulmonary or neurological disease.

- History of heart disease.

- History of psychiatric disease.

- Patients on drugs that modify CIMT (Statins, Aspirin, Angiotensin Converting Enzyme Inhibitor, Angiotensin receptor blocker).

- Pregnant women.

- Patient or patient's caretaker unable to respond satisfactorily to verbal questions.

- Refusal to provide informed consent.

\section{METHODOLOGY}

- $10 \mathrm{~mL}$ of fasting venous blood was collected from each participant in the fasting state (After overnight fasting of 12 hours and 3 days of fat free diet), $5 \mathrm{~mL}$ dispensed in clotted vial for estimation of total cholesterol, triglyceride and HDL-c, and $2 \mathrm{~mL}$ in ethylenediaminetetraacetic acid (EDTA) vial for estimation of HbA1c by High Performance 
Liquid Chromatography (HPLC), $3 \mathrm{~mL}$ in fluoride vial for estimation of fasting glucose. From the clotted blood, serum was separated and stored at $-20^{\circ} \mathrm{C}$.

- And $3 \mathrm{~mL}$ of postprandial venous blood was collected after 2 hours of having $75 \mathrm{~g}$ of glucose load and dispensed in the fluoride vial for estimation of postprandial glucose.

- Fasting and postprandial plasma glucose were estimated by Glucose oxidase-Peroxidase method. Total cholesterol was estimated by using cholesterol oxidase- Peroxidase method. Triglyceride was estimated by Glycerokinase Peroxidase- Peroxidase method. HDL cholesterol was estimated by direct method. Mindray kits were used for estimation of all these tests. Glycated haemoglobin or HbA1c was estimated by using High Performance Liquid Chromatography (HPLC) of Biorad D 10. LDL-c and VLDLc was estimated by Friedewald's formula.

- Carotid artery intima media thickness (CIMT) was measured by B-mode ultrasound on both the right and left carotid artery by an experienced radiologist blinded of other study data as per the guidelines of American Society of Echocardiography by ultrasonographic machine(GE Logic P 5). ${ }^{14}$ Three segments were measured in each side (Common Carotid Artery, Carotid Bulb Region and Internal Carotid Artery) and Composite CIMT was calculated by taking the mean of the right and left segmental mean thicknesses.

- All the participants have undergone detailed assessment of history, thorough physical examination and assessment of the biochemical parameters (as per our study protocol) and they are classified into three groups: Healthy, Prediabetes and Diabetes (newly diagnosed type 2 DM).

\section{STATISTICS}

The data obtained were analysed using the statistical software, SPSS version 16. Number of subjects and percentage of study population are compared across the groups using Pearson's Chi Square test. Mean \pm Standard Deviation of different parameters were compared across the 3 groups using One Way Analysis of Variance (ANOVA) Test. Association among continuous variables is captured by Pearson's Correlation coefficient. An alpha level of 5\% has been taken, i.e. if any $\mathrm{p}$ value is less than 0.05 it has been considered as significant.

\section{RESULTS}

$25 \%$ of participants are found to be apparently healthy or normoglycaemic, $33 \%$ prediabetic and $42 \%$ to be type $2 \mathrm{DM}$ patients (Newly Diagnosed) according to their fasting and postprandial plasma glucose levels and glycated haemoglobin (HbA1c) levels. The mean age of Healthy, Prediabetes and Diabetes groups are $49.85 \pm 8.53,51.56 \pm 10.62,55.49 \pm 10.34$ years respectively. One Way ANOVA test shows significant difference in the mean age of the three groups. Healthy group consists of $50 \%$ male and $50 \%$ female subjects, Prediabetes group consists of $44.44 \%$ male and $55.56 \%$ female subjects whereas Diabetes group consists of $49.12 \%$ male and $50.88 \%$ female subjects.

There is no significant difference in gender distribution between the three groups. The mean fasting glucose increased from Healthy $(84.18 \pm 8.04 \mathrm{mg} / \mathrm{dL})$ to Prediabetes $(110.09 \pm 5.88 \mathrm{mg} / \mathrm{dL})$ to Diabetes $(232.3 \pm 52.38 \mathrm{mg} / \mathrm{dL})$ with significant difference between the fasting glucose levels between the three groups. The mean post-prandial blood glucose increased from Healthy $(122.03 \pm 7.01 \mathrm{mg} / \mathrm{dL})$ to Prediabetes $(153.47 \pm 25.04 \mathrm{mg} / \mathrm{dL})$ to Diabetes (335.56 $\pm 86.79 \mathrm{mg} / \mathrm{dL})$ with significant difference among them. The mean HbA1c increased from Healthy $(5.13 \pm 0.28 \%)$ to Prediabetes $(6.1 \pm 0.19 \%)$ to Diabetes $(8 \pm 2.19 \%)$ with significant difference between them.

Mean total cholesterol, triglyceride, LDL-c and VLDL-c increased while, HDL-c decreased from Healthy to Prediabetes to Diabetes (Table 1 and Figure 1). One way ANOVA test shows significant difference in all of these between the Healthy, Prediabetes and Diabetes group.

The intima-media thickness of right common carotid artery (CCA RT), left common carotid artery (CCA LT), right carotid bulb region (BULB RT), left carotid bulb region (BULB LT) and the Composite value increased from Healthy to Prediabetes to Diabetes. One way ANOVA test shows significant difference of all the carotid intima media thickness (CIMT) values in the three groups. (Table 2 and Figure 2).

There is significant, strong and positive correlation noted between composite carotid intima-media thickness (CIMT) and Total Cholesterol in the Healthy and Diabetes group ( $p$ value $<0.001$ ) whereas, there is hardly any significant correlation noted in the Prediabetes group (Table $3)$.

There is significant, strong and positive correlation noted between triglyceride cholesterol level and Composite Carotid Intima Media Thickness (CIMT) in Healthy and Diabetes group ( $\mathrm{p}$ value $<0.001$ ) whereas, there is hardly any significant correlation noted in Prediabetes group (Table 4) There is significant, strong and negative correlation noted between composite carotid intima media thickness (CIMT) and HDL cholesterol in the Healthy and Diabetes group ( $\mathrm{p}$ value $<0.001$ ) whereas, there is hardly any significant correlation noted in Prediabetes group (Table 5). There is significant, strong and positive correlation noted between Composite carotid intima media thickness (CIMT) and LDL cholesterol in the Healthy and Diabetes group ( $p$ value $<0.001$ ) whereas, there is hardly any significant correlation noted in Prediabetes group (Table 6).

\section{DISCUSSION}

In our study, the mean fasting plasma glucose, mean postprandial plasma glucose, and mean glycated haemoglobin (HbA1c) levels have increased from Healthy to Prediabetes to Diabetes and this increase has been found statistically significant and our results are consistent with the studies done by Dullart et al. ${ }^{17}$ Ahsaan et al. ${ }^{18}$

Diabetic dyslipidaemia consists of increased hepatic secretion and impaired clearance of VLDL-c thus causing increased production of precursors of small dense LDL-c particles. ${ }^{19,20}$ In Type $2 \mathrm{DM}$, there is increased transfer of cholesterol from HDL-c to triglyceride rich lipoproteins, with reciprocal transfer of triglyceride to HDL-c leading to reductions in HDL-c levels. ${ }^{21}$ In our study, mean HDL-c levels have decreased from Healthy to Prediabetes to Diabetes, with results being consistent with that of by Samatha et al.22 Lalitha et al.23 Uttra et al.24

Hyperglycaemia leads to lesion initiation by causing infiltration of monocytes into the subendothelial space, and subsequent accumulation of lipid loaded macrophages. ${ }^{25,6}$ and recruitment of monocytes is regulated by endothelial adhesion molecules and their corresponding monocyte ligands mostly E-selectin, P-selectin, vascular cell adhesion 
molecule-1 (VCAM-1), and intracellular cell adhesion molecule-1 (ICAM-1). ${ }^{26}$ Progression from the fatty streak lesion to an advanced, clinically significant complex lesion encompasses encapsulation of the macrophage-rich mass by smooth muscle cells (SMCs) to form a fibrous cap, and the death of macrophages to form one or more necrotic cores, calcification of advanced plaque and intraplaque haemorrhage and rupture of thin-cap fibroatheromas and its thrombosis causes most of the clinical events in humans. ${ }^{27}$ The long-chain fatty acids (such as palmitate, oleate, and linoleate), and the oxidised phospholipids, which are present in modified LDL-c exerts an effect similar to that of glucose by inducing vascular cell adhesion molecule (VCAM-1) expression in macrovascular cells. ${ }^{28}$

Elevated glucose levels in human aortic endothelial cells also results in increased release of thromboxane B2.29 and prostaglandin E2.30 12(S)HETE (Hydroxyeicosatetraenoic acids). ${ }^{31}$ thus stimulating monocyte adhesion to cultured endothelial cells. ${ }^{32}$ Elevated glucose also results in increased activity of aldose reductase dependent sorbitol pathway, thus causing increased levels of Advanced Glycated End products (AGE). ${ }^{33}$ Moreover, there is increased production of reactive oxygen free radicals from mitochondrial oxidative phosphorylation in hyperglycaemia, causing cell damage. ${ }^{33}$ In our study, the mean CIMT of right common carotid artery, left common carotid artery, right bulb region, left bulb region and composite CIMT have increased from Healthy to Prediabetes to Diabetes, the difference being statistically significant. Results are consistent with the studies done by Kota et al ${ }^{34}$, Ahmed et al. ${ }^{35}$

Results are also consistent with studies done on prediabetics by Karbek et al. ${ }^{36}$ Parildar et al. ${ }^{37}$ In our study, the Composite CIMT strongly, positively and significantly correlates with the total cholesterol, triglyceride and LDL-c and negatively with HDL-c levels in the Healthy and Diabetic (Type 2 DM) subjects. But, there is hardly any significant correlation noted between composite CIMT and any of the lipid parameters in the Prediabetes group. Results are consistent with a study by Kota et al ${ }^{34}$ and also with the Kora F4 study. 38

Although early atherosclerotic lesions provide precursors for the formation of advanced complex plaques, these early lesions are not clinically significant and also sometimes regresses. ${ }^{39}$ Intermediate lesions and atheroma involve increased focal accumulation of lipid within the neo intima due to increased levels of foam cells. Complicated lesion forms when the plaque becomes disrupted due to fissure, haemorrhage or thrombus formation. ${ }^{6}$ Thus atherogenesis progresses in a chain reaction but, not in an uniform manner and it takes time to develop a lipid rich fibrous plaque core from proatherogenic dyslipidaemia. This may explain the insignificant correlation of lipid parameters with the Composite CIMT in the prediabetes population where, there is evidence of chronic hyperglycaemia and proatherogenic dyslipidaemia but the CIMT is not yet raised to that level.

In conclusion, findings of our study indicates that the biochemical changes of atherosclerosis start even before the onset of diabetes, in the prediabetes state only; thus emphasising the immense importance of prediabetes state as an atherosclerotic marker, in which, the precautionary measures can be taken for prevention of cardiovascular complications of diabetes in the future. So, we propose the need for further research in larger sample sizes in different population with different genetic factors owing to the small sample size of our study.

\begin{tabular}{|c|c|c|c|c|c|}
\hline & \multicolumn{3}{|c|}{ Status } & & \\
\cline { 2 - 6 } & Healthy & Prediabetes & Diabetes & & \\
\cline { 2 - 6 } & Mean \pm Std. Deviation & Mean \pm Std. Deviation & Mean \pm Std. Deviation & p Value & Significance \\
\hline Total Cholesterol & $126.97 \pm 11.24$ & $181.29 \pm 31.6$ & $230.89 \pm 26.13$ & $<0.001$ & Significant \\
\hline Triglyceride & $69.5 \pm 9.43$ & $132.29 \pm 50.28$ & $187.02 \pm 22.73$ & $<0.001$ & Significant \\
\hline LDL Cholesterol & $70.81 \pm 13.07$ & $114.05 \pm 26.64$ & $161.75 \pm 22.84$ & $<0.001$ & Significant \\
\hline HDL Cholesterol & $42.26 \pm 3.9$ & $40.78 \pm 6.09$ & $31.74 \pm 4.48$ & $<0.001$ & Significant \\
\hline VLDL Cholesterol & $13.9 \pm 1.89$ & $26.46 \pm 10.06$ & $37.40 \pm 4.55$ & $<0.001$ & Significant \\
\hline \multicolumn{7}{|c|}{ Table 1 } \\
\hline
\end{tabular}

Table 1: Shows the Mean Total Cholesterol, Triglyceride, Low Density Lipoprotein-Cholesterol (LDL-c), High Density LipoproteinCholesterol (HDL-c) and very low Density Lipoprotein-Cholesterol (VLDL-c)In Healthy, Prediabetes and Diabetes

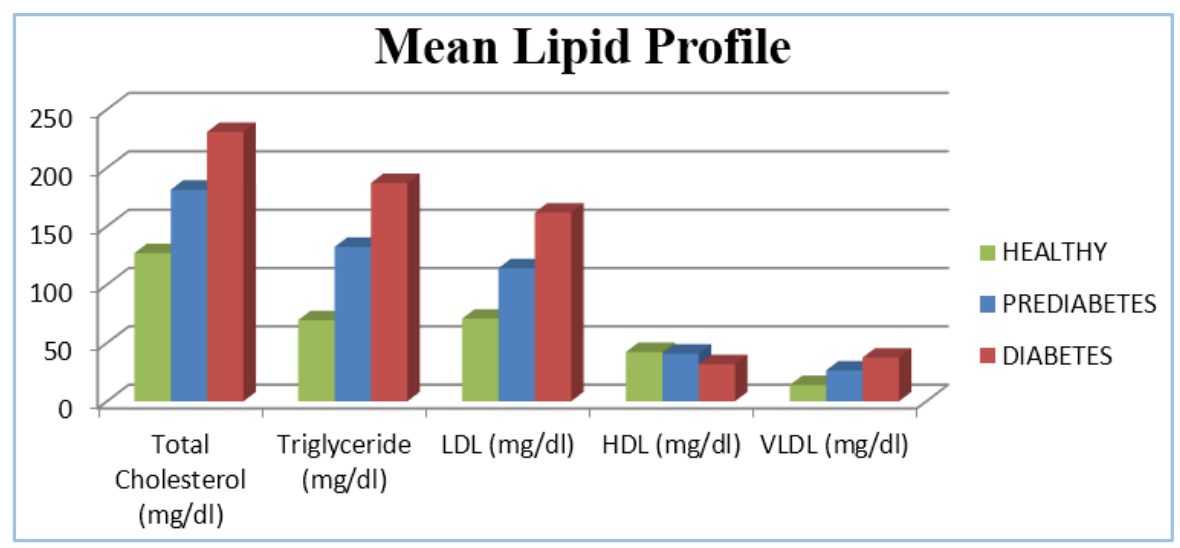

Fig. 1: Shows the Mean Total Cholesterol, Triglyceride, $L D L-c$, HDL-c and VLDL-c in Healthy, Prediabetes and Diabetes 


\begin{tabular}{|c|c|c|c|c|c|}
\hline & \multicolumn{3}{|c|}{ Status } & & \\
\cline { 2 - 6 } & HEALTHY & PREDIABETES & DIABETES & & \\
\cline { 2 - 6 } & Mean \pm Std. Deviation & Mean \pm Std. Deviation & Mean \pm Std. Deviation & p Value & Significance \\
\hline CCA RT CIMT(mm) & $0.57 \pm 0.08$ & $0.66 \pm 0.11$ & $1.17 \pm 0.12$ & $<0.001$ & Significant \\
\hline CCA LT CIMT(mm) & $0.56 \pm 0.07$ & $0.7 \pm 0.08$ & $1.14 \pm 0.13$ & $<0.001$ & Significant \\
\hline BULB RT CIMT (mm) & $0.58 \pm 0.07$ & $0.78 \pm 0.1$ & $1.16 \pm 0.12$ & $<0.001$ & Significant \\
\hline BULB LT CIMT(mm) & $0.56 \pm 0.06$ & $0.66 \pm 0.22$ & $1.13 \pm 0.14$ & $<0.001$ & Significant \\
\hline COMPOSITE CIMT(mm) & $0.56 \pm 0.06$ & $0.69 \pm 0.05$ & $1.14 \pm 0.1$ & $<0.001$ & Significant \\
\hline \multicolumn{7}{|c|}{ Table 2 }
\end{tabular}

Table 2: Shows mean Carotid Intima Media Thicknesses (CIMT) of Right Common Carotid Artery (CCA RT), Left Common Carotid Artery (CCA LT), Right Carotid Bulb Region (BULB RT), Left Carotid Bulb Region (BULB LT), and of the Composite Value in Healthy,

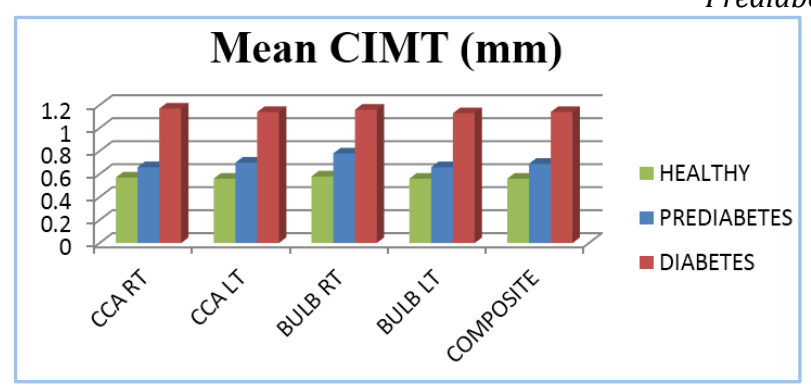

Fig. 2: Shows the Mean Carotid Intima Media Thickness (CIMT) of Right Common Carotid Artery (CCA RT), Left Common Carotid Artery (CCA LT), Right Carotid Bulb Region (BULB RT), Left Carotid Bulb Region (BULB LT) and of the Composite Value

\begin{tabular}{|c|c|c|c|}
\hline \multicolumn{3}{|c|}{ Status } & $\begin{array}{c}\text { Total } \\
\text { CHOLESTEROL }\end{array}$ \\
\hline Healthy & $\begin{array}{c}\text { Composite } \\
\text { CIMT }\end{array}$ & $\begin{array}{c}\text { Pearson } \\
\text { Correlation }\end{array}$ & 0.752 \\
\hline Prediabetes & $\begin{array}{c}\text { Composite } \\
\text { CIMT }\end{array}$ & $\begin{array}{c}\text { Pearson } \\
\text { Correlation }\end{array}$ & -0.375 \\
\hline Diabetes & $\begin{array}{c}\text { Composite } \\
\text { CIMT }\end{array}$ & $\begin{array}{c}\text { Pearson } \\
\text { Correlation }\end{array}$ & 0.618 \\
\hline $\begin{array}{c}\text { Table 3 : Shows Correlation of Composite Carotid } \\
\text { Intima Media Thickness (CIMT) with Total Cholesterol } \\
\text { in Healthy, Prediabetes and Diabetes }\end{array}$ \\
\hline
\end{tabular}

\begin{tabular}{|c|c|c|c|}
\hline \multicolumn{3}{|c|}{ Status } & Triglyceride \\
\hline Healthy & $\begin{array}{c}\text { Composite } \\
\text { CIMT }\end{array}$ & $\begin{array}{c}\text { Pearson } \\
\text { Correlation }\end{array}$ & 0.683 \\
\hline Prediabetes & $\begin{array}{c}\text { Composite } \\
\text { CIMT }\end{array}$ & $\begin{array}{c}\text { Pearson } \\
\text { Correlation }\end{array}$ & -0.493 \\
\hline Diabetes & $\begin{array}{c}\text { Composite } \\
\text { CIMT }\end{array}$ & $\begin{array}{c}\text { Pearson } \\
\text { Correlation }\end{array}$ & 0.538 \\
\hline $\begin{array}{c}\text { Table 4: Shows Correlation of Composite Carotid Intima } \\
\text { Media Thickness (CIMT)with Triglyceride Level in } \\
\text { Healthy, Prediabetes and Diabetes }\end{array}$ \\
\hline
\end{tabular}

\begin{tabular}{|c|c|c|c|}
\hline \multicolumn{3}{|c|}{ Status } & \multirow{2}{*}{$\begin{array}{c}\text { HDL } \\
-0.653\end{array}$} \\
\hline Healthy & $\begin{array}{c}\text { Composite } \\
\text { CIMT }\end{array}$ & $\begin{array}{c}\text { Pearson } \\
\text { Correlation }\end{array}$ & \\
\hline Prediabetes & $\begin{array}{l}\text { Composite } \\
\text { CIMT }\end{array}$ & $\begin{array}{c}\text { Pearson } \\
\text { Correlation }\end{array}$ & 0.222 \\
\hline Diabetes & $\begin{array}{c}\text { Composite } \\
\text { CIMT }\end{array}$ & $\begin{array}{c}\text { Pearson } \\
\text { Correlation }\end{array}$ & -0.455 \\
\hline \multicolumn{4}{|c|}{$\begin{array}{l}\text { Table 5: Shows Correlation of Composite Carotid } \\
\text { Intima Media Thickness (CIMT)with the HDL } \\
\text { Cholesterol Level in Healthy, Prediabetes and Diabetes }\end{array}$} \\
\hline
\end{tabular}

\begin{tabular}{|c|c|c|c|}
\hline \multicolumn{3}{|c|}{ Status } & LDL \\
\hline Healthy & $\begin{array}{c}\text { Composite } \\
\text { CIMT }\end{array}$ & $\begin{array}{c}\text { Pearson } \\
\text { Correlation }\end{array}$ & 0.743 \\
\hline Prediabetes & $\begin{array}{c}\text { Composite } \\
\text { CIMT }\end{array}$ & $\begin{array}{c}\text { Pearson } \\
\text { Correlation }\end{array}$ & -0.309 \\
\hline Diabetes & Composite & Pearson & 0.690 \\
\hline
\end{tabular}

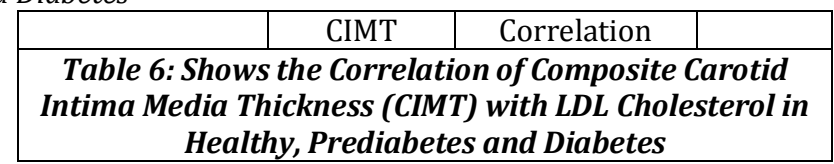

\section{REFERENCES}

1. Bennett PH, Knowler WC. Definition, diagnosis, and classification of diabetes mellitus \& glucose homeostasis. In: Kahn CR, Weir GC, King GL, et al. editors. Joslin's diabetes mellitus. New Delhi, India. Wolters Kluwer (India) Pvt. Ltd. Indian Reprint 2011, $2005 ; 14^{\text {th }}$ ed.

2. International diabetes federation. IDF Diabetes Atlas Sixth Edition: 2014 update [Internet]. Brussels, Belgium:2014 [updated 2014; cited 2015 Aug 15]. Available http://www.idf.org/diabetesatlas/update-2014.

3. Lewis GF, Steiner G. Hypertriglyceridemia and its metabolic consequences as a risk factor for atherosclerotic cardiovascular disease in non-insulin dependent diabetes mellitus. Diabetes Metab Rev 1996;12(1):37-56.

4. Solano MP, Goldberg RB. Lipid management in type 2 diabetes. Clinical Diabetes 2006;24(1):27-32.

5. Stary HC, Chandler AB, Glagov S, et al. A definition of initial, fatty streak, and intermediate lesions of atherosclerosis a report from the committee on vascular lesions of the council on arteriosclerosis, American heart association. Circulation 1994;89(5):2462-78. doi: 10.1161/01.CIR.89.5.2462.

6. Stary HC, Chandler AB, Dinsmore RE, et al. A definition of advanced types of atherosclerotic lesions and a histological classification of atherosclerosis a report from the committee on vascular lesions of the council on arteriosclerosis, American heart association. Circulation 1995;92(5):1355-74. doi: 10.1161/01.CIR.92.5.1355.

7. Natali A, Vichi S, Landi P, et al. Coronary atherosclerosis in type II diabetes: angiographic findings and clinical outcome. Diabetologia 2000;43(5):632-41.

8. American diabetes association. Standards of medical care in diabetes-2010. Diabetes Care 2010;33:S11-61.

9. National diabetes data group. Classification and diagnosis of diabetes mellitus and other categories of glucose intolerance. Diabetes 1979;28(12):1039-57.

10. Mann DM, Carson AP, Shimbo D, et al. Impact of A1C screening criterion on the diagnosis of pre-diabetes among U.S adults. Diabetes Care 2010;33(10):2190-5.

11. The expert committee on the diagnosis and classification of diabetes mellitus. Report of the expert committee on the diagnosis and classification of diabetes mellitus. Diabetes Care 1997;20(7):1183-97. 
12. Coutinho M, Gerstein HC, Wang Y, et al. The relationship between glucose and incident cardiovascular events a metaregression analysis of published data from 20 studies of 95,783 individuals followed for 12.4 years. Diabetes Care 1999;22(2):233-40.

13. Naghavi M, Falk E, Hecht HS, et al. Asymptomatic atherosclerosis: pathophysiology, detection and treatment. In: Naghavi M, editor. New York city: Humana Press; 2011; Chapter 39, From vulnerable plaque to vulnerable patient- part III. [Cited 2015 Sept, 15]. Available from:

http://www.springer.com/us/book/9781603271783\#. eBook ISBN: 978-1-60327-179-0. DOI: 10.1007/978-160327-179-0.

14. Stein JH, Korcarz CE, Hurst RT, et al. Use of carotid ultrasound to identify subclinical vascular disease and evaluate cardiovascular disease risk: a consensus statement from the American society of echocardiography carotid intima-media thickness task force endorsed by the society for vascular medicine. J Am Soc Echocardiogr 2008;21(2):93-111. doi: 10.1016/j.echo.2007.11.011.

15. Bots ML, Dijk JM, Oren A, et al. Carotid intima-media thickness, arterial stiffness and risk of cardiovascular disease: current evidence. J Hypertens 2002;20(12):2317-25.

16. The international expert committee. International expert committee report on the role of the A1C assay in the diagnosis of diabetes. Diabetes Care 2009;32(7):1327-34. Doi: 10.2337/dc09-9033.

17. Dullart RPF, De Vries R, Van Tol A, et al. Plasma adiponectin is a marker of increased intima-media thickness associated with type 2 diabetes mellitus and with male gender. European Journal of Endocrinology 2007;156(3):387-94.

18. Ahsan S, Ahmed S, Ahmed SD, et al. Status of serum adiponectin related to insulin resistance in prediabetics. J Pak Med Assoc 2014;64(2):184-8.

19. Krauss RM. Atherogenicity of triglyceride- rich lipoproteins. Am J Cardiol1998;81(4A):13B-17.

20. Krauss RM. Triglycerides and atherogenic lipoproteins: rationale for lipid management. Am J Med 1998;105(1A):58S-62.

21. Hopkins GJ, Barter PJ. Role of triglyceride- rich lipoproteins and hepatic lipase in determining the particle size and composition of high density lipoproteins. J Lipid Res 1986;27(12):1265-77.

22. Samatha P, Venkateswarlu M, Siva Prabodh V. Lipid profile levels in type 2 diabetes mellitus from the tribal population of adilabad in Andhra Pradesh, India. Journal of Clinical and Diagnostic Research 2012;6(4):593-96.

23. Lalitha P, Anjaneya Prasad V, Pradeep Babu K. Lipid patterns in prediabetic and diabetic patients in rural tertiary care centre. Int J Biol Med Res 2013;4(2):318184.

24. Uttra KM, Devrajani BR, Shah SZA, et al. Lipid profile of patients with diabetes mellitus (a multidisciplinary study). World Applied Sciences Journal 2011;12(9):1382-84.
25. Virmani R, Kolodgie FD, Burke AP, et al. Lessons from sudden coronary death : a comprehensive morophological classification scheme for atherosclerotic lesions. Arterioscler Thromb Vasc Biol 2000;20(5):1262-75.

26. Quehenberger 0 . Thematic review series: the immune system and atherogenesis molecular mechanisms regulating monocyte recruitment in atherosclerosis. J Lipid Res 2005;46(8):1582-90.

27. Virmani R, Burke AP, Farb A, et al. Pathology of the vulnerable plaque. J Am Coll Cardiol 2006;47(8):C13-8.

28. Cacicedo JM, Yagihashi N, Keaney JF Jr, et al. AMPK inhibits fatty acid-induced increases in NF-B transactivation in cultured human umbilical vein endothelial cells. Biochem Biophys Res Commun 2004;324(4):1204-9.

29. Cosentino F, Eto M, De Paolis P, et al. High glucose causes upregulation of cyclooxygenase- 2 and alters prostanoid profile in human endothelial cells: role of protein kinase $\mathrm{C}$ and reactive oxygen species. Circulation 2003;107(7):1017-23.

30. Sheu ML, Ho FM, Yang RS, et al. High glucose induces human endothelial cell apoptosis through a phosphoinositide 3-kinase-regulated cyclooxygenase-2 pathway. Arterioscler Thromb Vasc Biol 2005;25(3):539-45.

31. Brown ML, Jakubowski JA, Leventis LL, et al. Elevated glucose alters eicosanoid release from porcine aortic endothelial cells. J Clin Invest 1988;82(6):2136-41.

32. Patricia MK, Kim JA, Harper CM, et al. Lipoxygenase products increase monocyte adhesion to human aortic endothelial cells. Arterioscler Thromb Vasc Biol 1999;19(11):2615-22.

33. Brownlee M. The pathobiology of diabetic complications: a unifying mechanism. Diabetes 2005;54(6):1615-25.

34. Kota SK, Mahapatra GB, Kota SK, et al. Carotid intima media thickness in type 2 diabetes mellitus with ischemic stroke. Indian J Endocr Metab 2013;17(4):71622.

35. Ahmad J, Ahmed F, Siddiqui MA, et al. Inflammatory markers, insulin resistance and carotid intima-media thickness in north-Indian type 2 diabetic subjects. JAPI 2007;55:693-9.

36. Karbek B, Cakal E, Cakir E, et al. Cardiovascular risk factors, carotid artery intima media thickness, and hSCRP levels in patients with impaired glucose metabolism. Minerva Endocrinol 2013;38(3):297-304.

37. Parildar H, Gulmez O, Cigerli 0, et al. Carotid artery intima media thickness and hscrp; predictors for atherosclerosis in prediabetic patients? Pak J Med Sci 2013;29(2):495-9.

38. Kowall B, Ebert N, Then C, et al. Associations between blood glucose and carotid intima-media thickness disappear after adjustment for shared risk factors: the KORA F4 study. PLoS ONE 2012;7(12):e52590. doi:10.1371/journal.pone.005.

39. Strong JP, Malcom GT, McMahan CA, et al. Prevalence and extent of atherosclerosis in adolescents and young adults: implications for prevention from the pathobiological determinants of atherosclerosis in youth study. JAMA 1999;281(8):727-35. 